926

\section{SOME TRACE ELEMENTS AND OXIDATIVE STATUS IN CHILDREN WITH DOWN SYNDROME AND THE EFFECT OF EARLY INTERVENTION PROGRAM}

\author{
A.M. Okaly ${ }^{1}$, A.M. Amnaina ${ }^{2}$, O. El Shourbagy ${ }^{3}$ \\ ${ }^{1}$ Medical Department, ${ }^{2}$ Paediatrics, ${ }^{3}$ Community \\ Depatment, Omer Al-Mukhtar University, \\ Derna, Libya
}

Objectives: To measure some blood trace elements, oxidative enzymes and the effect of an intervention program among disabled children with Down Syndrome.

Methodology: This case control study included 60 children (30 cases with Down syndrome from outpatient clinics and care center for children with special needs, Derna) and 30 controls matched for age and sex, from January to December 2007. All cases were subjected to measuring blood selenium, copper, superoxide dismutase(SOD), glutathione peroxidase, evaluation of all the developmental fields (infant-stimulation, cognition, motor, social maturation, and language), a comprehensive program for early intervention using Portage Developmental Charts. Ethical consecrations were taken.

Results: The mean values of blood copper, erythrocyte SOD and glutathione peroxidase were significantly higher in cases with Down Syndrome than the controls $(1.9 \pm 0.2,1.6 \pm 0.2 \mathrm{mg} / \mathrm{L}, 407 \pm 155$, $133 \pm 54 \mathrm{U} / \mathrm{L}, \quad 13457+2175, \quad 6671 \pm 2105 \mathrm{U} / \mathrm{L}$, respectively, while blood selenium was significantly lower in Down Syndrome than controls $(14.3 \pm 0.9$, $19.7 \pm 1.3 \mathrm{ug} / \mathrm{L}$, respectively $)(\mathrm{P}<0.05)$.

The mean value of social, self-help, cognition and motor developmental fields in Down Syndrome were significantly improved after the intervention program than before $((77.3 \pm 13,78.1 \pm 15,61.2 \pm 21,66.8 \pm 17$, $66.3 \pm 14,73.5 \pm 20,44 \pm 19,52.6 \pm 22$, respectively, $\mathrm{P}<$ $0.05)$.

Conclusion: Implementationofearlycomprehensive intervention programs is mandatory for the children who suffer from problems related to developmental fields and detecting any metabolic or molecular disorders could be prevented or treated by correction or replacement.

Keywords: Down Syndrome, Mental Retardation, Early Intervention, Trace elements, Oxidative status

\section{7}

\section{1-YEAR FOLLOW-UP OF THE CCC2000 BIRTH COHORT: DEVELOPMENTAL PATHWAYS OF PSYCHOPATHOLOGY AND IDENTIFICATION OF 'AT RISK' MENTAL STATES IN CHILDREN}

\author{
C. Eberhardt ${ }^{1}$, P. Jeppesen ${ }^{1}$, A. Munkholm¹, N.
} Micali $^{2}$, E.M. Olsen ${ }^{3}$, H. Elberling ${ }^{4}$, C.U. Rask ${ }^{5}$, A.M. Skovgaard ${ }^{1}$, CCC2000 study group $^{2}$

${ }^{1}$ Research Unit, Child and Adolescent Psychiatric Center Glostrup, Glostrup, Denmark, ${ }^{2}$ Institute of Psychiatry, King's College London, London, UK, ${ }^{3}$ Child- and Adolescent Psychiatric Center Bispebjerg, Copenhagen, ${ }^{4}$ Child and Adolescent Psychiatric Center Glostrup, Glostrup, ${ }^{5}$ Psychiatric Hospital for Children and Adolescents, University of Aarhus, Aarhus, Denmark

The knowledge of developmental pathways of mental health disorders in childhood is limited. The Copenhagen Child Cohort CCC 2000 was established in Denmark in year 2000 to study developmental psychopathology prospectively from birth in an unselected birth cohort. The early studies of the cohort have found that risk mechanisms and signs of psychopathology can be identified from early infancy. The 5-7 year follow-up of CCC 2000 has determined the prevalence and pattern of comorbidity of all common mental health disorders in that age group; and studies of associated early developmental, neurobiological and psychosocial risk factors are in progress. The 11-year followup study will expand the prospective study of developmental psychopathology to an age where neuro-developmental disorders, e.g. ADHD, are manifest and where early symptoms of adolescent psychopathology, e.g. schizophrenia, somatoform disorders and eating disorders, appear. The aim is to determine the prevalence of mental health disorders in 11 year old children, describe the risk factors involved, and describe the developmental pathways of mental health problems from early infancy across childhood into preadolescence. The CCC2000 birth cohort, consisting of 6090 children, will be investigated at age 11 . Key measures are questionnaires filled in electronically by child, parent and teacher. The questionnaires assess general and specific items of psychopathology in children. Additionally, a health examination will be carried out at the school and a subgroup of children will be invited for a semi-structured interview. The database will link to several Danish registers. Data analyses and publication will take place in 2012-2013 